\title{
Epidemiological, Clinical and Therapeutic Profiles of Ophthalmological Complications of Rhino-Sinusitis in a Tertiary Facility in Black Africa
}

\author{
Alpha Oumar Diallo1*, Ramata Balde², Oumar Raphiou Diallo³, Ismael Dabo', Alimou Sinayoko², \\ Kadiatou Porédaka Diallo²
}

${ }^{1}$ ENT Department, Ignace Deen National Hospital, Conakry, Guinea

${ }^{2}$ Ophthalmology Department, Ignace Deen National Hospital, Conakry, Guinea

${ }^{3}$ Department of Stomatology and Maxillofacial Surgery, Donka National Hospital, Conakry, Guinea

Email: *dalphao@hotmail.com

How to cite this paper: Diallo, A.O., Balde, R., Diallo, O.R., Dabo, I., Sinayoko, A. and Diallo, K.P. (2021) Epidemiological, Clinical and Therapeutic Profiles of Ophthalmological Complications of Rhino-Sinusitis in a Tertiary Facility in Black Africa. International Journal of Otolaryngology and Head \& Neck Surgery, 10, 222-228.

https://doi.org/10.4236/ijohns.2021.103020

Received: April 19, 2021

Accepted: May 22, 2021

Published: May 25, 2021

Copyright $\odot 2021$ by author(s) and Scientific Research Publishing Inc. This work is licensed under the Creative Commons Attribution International License (CC BY 4.0).

http://creativecommons.org/licenses/by/4.0/

\begin{abstract}
Introduction: Rhinosinusitis is one of the most common ENT diseases. Its main complications are of three types: cranial, endo-cranial and ophthalmological. The aim of this study was to contribute to the study of ophthalmological complications of rhino-sinusitis in our context. Material and Methods: This was a prospective study, of descriptive type, of six (6) months (July-December 2017), concerning the patients received and treated for ophthalmological complications of rhino-sinusitis at the National IgnaceDeen Hospital. Results: During our study period, we collected 32 ophthalmological complications of rhinosinusitis, i.e. $65.31 \%$ of cases. The average age of our patients was $34.25 \pm 15.15$ years with extremes of 8 and 76 years and a sex ratio of 0.45. A history of rhinitis and/or rhino-sinusitis was reported in all our patients. Housewives were the most affected socio-professional group, accounting for $34.37 \%$ of cases. The average consultation time was $20 \pm 52$ days. Tearing, palpebral oedema and purulent rhinorrhea were present in all our patients. Preseptal cellulitis and abscess were the most common complications, accounting for $56.25 \%$ and $28.12 \%$ of cases respectively. The treatment was medical-surgical. Drainage of a subperiosteal abscess of the ethmoid involved $53.12 \%$ of cases. Surgical treatment of the maxillary sinus and/or ethmoid by endoscopy was sometimes associated. The evolution was favourable in all cases. Conclusion: Ophthalmological complications of rhino-sinusitis are still frequent in our developing countries. Their management must be multidisciplinary.
\end{abstract}




\section{Keywords}

Complications, Ophthalmologic, Rhino-Sinusitis, Conakry

\section{Introduction}

Rhinosinusitis is the inflammation, most often of infectious origin, of the nasal mucosa and paranasal air cavities. It is one of the most frequently encountered pathologies in Otolaryngology (ENT) [1]. The main complications are of three types: cranial, endo-cranial and ophthalmological. The latter, the most frequent complication of rhino-sinusitis, is linked to the fact that the paranasal sinuses, which surround the orbit on three walls (inferior, internal and superior), are separated from it by bony partitions that are dehiscent in places, thus constituting a random barrier against the extension of infections from the sinuses into the orbital cavities. The role of sinusitis is therefore universally recognized as an important etiology of orbital infections. It accounts for $60 \%$ of all diseases of the orbit and $60 \%-80 \%$ of oculo-orbital inflammatory diseases [2] [3]. The main ophthalmological complications of rhino-sinusitis (OCRS) include subperiosteal abscesses and orbital cellulitis (preseptal and post-septal). In Cameroon, Ahounkeng Nanda $\mathrm{P}$ et al. in their study of sinus pathologies in children in Yaoundé reported $66.67 \%$ ophthalmological complications including $50 \%$ orbital cellulitis (3 cases) and $16.67 \%$ periorbital abscesses [4]. In Morocco Daoudi A et al. [5] found $85 \%$ of preseptal cellulitis and $15 \%$ of retrospective cellulitis. The aim of this series was to analyze the epidemiological, clinical and therapeutic aspects of ophthalmological complications of rhino-sinusitis in our context.

\section{Material and Methods}

This was a prospective study, of descriptive type, of a duration of six (06) months, going from July 1 to December 31, 2017. It focused on a series of ophthalmological complications of rhino-sinusitis collected in the ENT and Ophthalmology departments of the IgnaceDeen National Hospital. We included in this series, all patients received and managed in our services for an OCRS, during the study period. Recruitment was exhaustive. For each patient, we noted age, sex, personal and family history, profession, time and reason for consultation. Complete ENT and ophthalmological examinations were performed, sometimes supplemented by medical imaging (digital radiography, CT scan). General, neurological and stomatological examinations to exclude an extra-sinusal infection were also performed. We considered that there was an ophthalmological complication of rhino-sinusitis when a conjunctival or orbital infection was associated with and/or preceded by rhino-sinusitis in the absence of other infectious sites. Conjunctival or ocular inflammations for which the role of rhino-sinusitis as an aetiology was questionable were excluded. The treatment was medico-surgical, both ophthalmologic, stomatologic and ENT. Progress was assessed after one year. 
The Ethics Committee of the Faculty of Health Sciences and Techniques of the University of Conakry approved the study. Our data were processed using SPSS software.

The limitation of the study was the financial inaccessibility of some patients to paraclinical examinations such as CT scans, which are still very expensive for our populations. The indications for CT scan were therefore well specified with clinical criteria relating to significant palpebral edema with eye closure, exophthalmos and/or palpation of a fluctuating mass or even the presence of pus at the internal angle of the eye.

\section{Results}

Of the 881 patients admitted for rhino-sinusitis during our study period, we counted 49 complications, of which 32 were ophthalmological, i.e. $65.31 \%$ of cases. We report, through this prospective study, 32 patients with ophthalmological complications of rhino-sinusitis (OCRS).

The average age of our patients was $34.25 \pm 15.15$ years, with extremes of 8 and 76 years. We observed a female predominance with a sex ratio of 0.45 . Housewives represented $34.37 \%(n=11)$ of the cases. The risk factors were dominated by rhinitis and/or rhino-sinusitis, reported in all our patients (Table 1).

Table 1. Socio-demographic characteristics.

\begin{tabular}{|c|c|c|}
\hline Characteristics & Number & Percentage (\%) \\
\hline \multicolumn{3}{|l|}{ Age } \\
\hline$<20$ & 4 & 12.50 \\
\hline 21 à 40 & 22 & 68.75 \\
\hline$>40$ & 6 & 18.75 \\
\hline \multicolumn{3}{|l|}{ Sex } \\
\hline Female & 22 & 68.75 \\
\hline Male & 10 & 31.25 \\
\hline \multicolumn{3}{|l|}{ Occupations } \\
\hline Housewife & 11 & 34.37 \\
\hline Civil servant & 10 & 31.25 \\
\hline Student/Pupil & 7 & 21.88 \\
\hline Self-employed ${ }^{*}$ & 4 & 12.50 \\
\hline \multicolumn{3}{|l|}{ Risk factors } \\
\hline Rhinitis/Rhino-sinusitis & 32 & 100 \\
\hline Type 2 diabetes & 6 & 18.75 \\
\hline Smoking & 3 & 9.37 \\
\hline Nasosinus polyposis & 1 & 3.12 \\
\hline Total & 32 & 100 \\
\hline
\end{tabular}

${ }^{\star}$ Merchants, hairdresser worker. 
The delay in consultation ranged from 10 days to 90 days with a mean delay of $20 \pm 52$ days. The clinical characteristics of the patients are summarized in Table 2.

Analysis of the radiological findings (CT and/or digital skull radiographs, Blondeau or face up) noted isolated maxillary involvement in $34.37 \%(n=10)$ of cases. The other attacks always involved the ethmoid (Table 3).

These different sinus attacks led to ophthalmological complications which we have summarized in Table 4.

Table 2. Distribution of patients according to reasons for consultation $(\mathrm{N}=32)$.

\begin{tabular}{ccc}
\hline Reasons for consultation & Number & Percentage \\
\hline Watery eyes & 32 & 100 \\
Rhinorrhoea & 32 & 100 \\
Nasal obstruction & 32 & 100 \\
Pus in the middle meatus & 32 & 100 \\
Headache & 31 & 96.87 \\
Conjunctival hyperaemia & 22 & 68.75 \\
Decreased visual acuity & 20 & 62.50 \\
Palpebral oedema & 15 & 46.87 \\
Release of pus at lacrimal points & 12 & 37.50 \\
Corneal ulceration & 7 & 21.87 \\
Poor oral status & 11 & 34.37 \\
\hline
\end{tabular}

Table 3. Distribution of patients according to facial sinus involvement.

\begin{tabular}{ccc}
\hline Anatomical lesion & Number & Percentage (\%) \\
\hline Isolated jaw & 11 & 34.37 \\
Ethmoido-maxillary & 10 & 31.25 \\
Ethmoido-maxillo-frontal & 6 & 18.75 \\
Ethmoidal & 5 & 15.63 \\
Total & 32 & 100
\end{tabular}

Table 4. Distribution of ophthalmological complications of rhinosinusitis.

\begin{tabular}{ccc}
\hline Complications & Number & Percentage \\
\hline Preseptal cellulitis & 18 & 56.25 \\
Preseptal abscess & 9 & 28.12 \\
Orbital cellulitis & 2 & 6.25 \\
Subperiosteal abscess & 2 & 6.25 \\
Dacryocysto-keratitis & 1 & 3.12 \\
Total & 32 & 100 \\
\hline
\end{tabular}


Bacteriology of the pus taken from the internal angle of the eye or during surgery was sterile in all cases. The biology showed a high CRP level with a median CRP of $70 \mathrm{mg} / \mathrm{l}$ and extremes of 21 and $215 \mathrm{mg} / \mathrm{l}$. The mean polynucleosis was $14,000 / \mathrm{mm}^{3}$ with extremes of 10,000 and $19,000 / \mathrm{mm}^{3}$.

All patients in our series had received medical treatment with parenteral antibiotics for an average of 7 days, followed by oral treatment for 7 to 10 days. The most commonly used antibiotics were third generation cephalosporin, amoxicillin-clavulanic acid, aminoglycosides and imidazole. We recommended dual therapy in most cases and an imidazole was added in cases of suspected anaerobic infection to broaden the spectrum of action. Adjuvant treatment systematically included nasal cavity lavage and blowing followed by aerosol therapy, nasal decongestant in $75 \%(\mathrm{n}=24)$ of cases, antibiotic and anti-inflammatory eye drops in $68.75 \%(\mathrm{n}=22)$ of patients, analgesics/antipyretics, corticosteroids in $56.25 \%$ $(n=18)$ of cases, and treatment of the dental cause in $50 \%(n=16)$ of patients.

Surgical treatment included drainage of the purulent collection (palpebral and/or septal drainage), sometimes extended to the maxillary sinus (middle meatotomy) and ethmoid by endoscopy in $56.25 \%(\mathrm{n}=18)$ of cases, and decompression by internal orbitotomy in $12.50 \%(n=4)$ of cases.

The evolution was marked by the persistence, for several months, of signs of clinical naso-sinusal dysfunction, with good local evolution under symptomatic treatment in $31.25 \%(\mathrm{n}=10)$ of cases. The long-term evolution had been favourable in all patients.

\section{Discussion}

Ophthalmological complications of rhino-sinusitis are relatively common in our practice. In this study, we observed 32 cases of ophthalmologic complications of rhino-sinusitis. However, this is a hospital-based frequency. It should be higher in the general population because not only was our study mono-centric, not including patients treated in other ENT and ophthalmology departments in the country, but also patients treated by traditional practitioners. Laure B et al. [4] reported that ophthalmological infections constituted $80 \%$ of the complications of rhino-sinusitis.

The female predominance in our study is comparable to the series by Daoudi A et al. [5], who found a female majority of $58 \%$ with a sex ratio of 0.78 , but different from the data reported by most authors [6] [7].

Most of our patients were young adults with a mean age of 34.25 years. Our result is superior to that of Ben Amor M et al. who reported a mean age of 15.75 years with extremes of 1 and 59 years [8].

Oculo-orbital infections are manifested by the inflammatory reactions observed in the eye and orbit rather than by orbital cellulitis, which is less frequent but more serious [9].

Delayed consultation was evident with an almost systematic history of allergic rhinitis and chronic sinusitis and dental extractions in half of the cases. Chahed 
$\mathrm{H}$ et al. [7] in their series found a mean delay in consultation of 7.68 days.

On physical examination, our results were comparable to those of Manpreet Singh et al. [3] who reported that all their patients had eyelid edema, conjunctival congestion and chemosis.

In contrast to our series, where the ophthalmological complications of rhino-sinusitis were dominated by pre septal cellulitis and pre septal abscess, Bejor UN et al. [10] found exposure keratopathy, increased intraocular pressure, central retinal artery or vein occlusion and optic neuropathy as ocular complications. This confirms the hypothesis that the types of complications vary according to the initial anatomical involvement, which was mainly maxillary and ethmoid in our series. The thinness of the bony walls that separate the sinus cavities from the orbital structures accounts for the diffusion of the infection to this organ. Anatomical variations such as spontaneous dehiscence of the papyraceous blades of the sinus walls also facilitate the spread of the infection to the orbit [11]. Our results differ from those of Ben Amor $\mathrm{M}$ et al. [8] who reported fronto-ethmoid-maxillary sinus involvement in $38.23 \%$ and ethmoid-maxillary in $20.58 \%$ of cases.

The management of CORS is multidisciplinary, involving the ENT specialist, the ophthalmologist, the stomatologist, the radiologist and the infectious diseases specialist. It is a therapeutic emergency, which is always based on medical treatment (broad-spectrum antibiotics, analgesics/antipyretics and nasal drops and eye drops), combined or not with surgical treatment and dental care. This medical treatment was supplemented by nasal lavage and aerosol therapy. Manpreet Singh et al. [3] reported the same protocol in the management of their patients.

Surgical treatment was directed at the ophthalmic complication (palpebral or septal drainage) and the sinus focus. This allowed the sinus cavities to be ventilated, their contents to be drained and, if necessary, bacteriological samples to be taken.

The favourable evolution of our patients is comparable to the series of Chahed $\mathrm{H}$ et al. [7] who reported a $93.1 \%$ favourable outcome.

\section{Conclusion}

Ophthalmological complications of rhino-sinusitis are still relatively frequent in our developing countries. The clinical signs observed in our series made it possible to specify that it was a \pm serious attack of the eye. Medical imaging helped in the management. These complications constitute a diagnostic and therapeutic emergency whose management must be multidisciplinary.

\section{Conflicts of Interest}

The authors declare no conflicts of interest regarding the publication of this paper.

\section{References}

[1] Moussala, M., Meli, J., Bengono, G., Binam, F. and EkekeMonono, M. (1998) Ocu- 
lo-Orbital Complications of Acute Sinusitis in Ophthalmological Consultation in Cameroon: Epidemiological Aspects and Associated Mortality. Médecine d Afrique noire, 45, 110-114.

[2] Singh, M., Negi, A., Zadeng, Z., Verma, R. and Gupta, P. (2019) Long-Term Ophthalmic Outcomes in Pediatric Orbital Cellulitis: A Prospective, Multidisciplinary Study from a Tertiary Care Referral Institute. Journal of Pediatric Ophthalmology \& Strabismus, 56, 333-339. https://doi.org/10.3928/01913913-20190807-01

[3] Laure, B., Tiguemounine, J., Picard, A. and Goga, D. (2004) Intraorbital Abscesses of Dental Origin. Revue de Stomatologie et de Chirurgie Maxillo-faciale, 105, 125-129. https://doi.org/10.1016/S0035-1768(04)72290-1

[4] Nanda, A.P., Obama, A.M.T., Ndjolo, A., Ngaba, O.N., Onana, F.A. and Bengono, T.G. (2005) Sinus Pathology in Children in Yaounde: Clinical, Paraclinical and Evolutionary Aspects. Revue Africaine d ORL et de Chirurgie Cervico-faciale des pays francophones d Afrique, 3, 42-48.

[5] Daoudi, A., Ajdakar, S., Rada, N., Draiss, G., Hajj, I. and Bouskraoui, M. (2016) Orbital and Periorbital Cellulitis in Children. Epidemiological, Clinical, Therapeutic Aspects and Course. Journal Français d Ophtalmologie, 39, 609-614. https://doi.org/10.1016/j.jfo.2016.05.008

[6] Oxford, L.E. and McClay, J. (2005) Complications of Acute Sinusitis in Children. Otolaryngology-Head and Neck Surgery, 133, 32-37. https://doi.org/10.1016/j.otohns.2005.03.020

[7] Chahed, H., Bachraoui, R., Kedous, S., Ghordel, H., Houcine, A., Mediouni, A., Marrakchi, J., Zainine, R., Amor, B.M., Beltaief, N. and Besbes, G. (2014) Management of Oculolar and Orbital Complications of Acute Sinusitis. Journal Français d Ophtalmologie, 37, 702-706. https://doi.org/10.1016/j.jfo.2014.02.010

[8] Amor, B.M., Khalifa, Z., Romdhane, N., Zribi, S., Gamra, B.O., Mbarek, C. and El Khédim, A. (2013) Orbital Complications of Sinusitis. Journal Français d Ophtalmologie, 36, 488-493. https://doi.org/10.1016/j.jfo.2012.06.027

[9] Amat, F. (2010) Complications of Bacterial Rhino-Sinusitis in Children: A Case Report and Review of the Literature. Archives de Pédiatrie, 17, 258-262. https://doi.org/10.1016/j.arcped.2009.11.012

[10] Bajor, U.N., Lang, C.P., Bültmann, E., Framme, C. and Hufendiek, K. (2017) Orbital Complication of Acute Sinusitis: Orbital Cellulitis in a 10-Year-Old Child. Der Ophthalmologe, 114, 365-369. https://doi.org/10.1007/s00347-016-0296-7

[11] Hammami, B., Masmoudi, M., Charfeddine, I., Mnejja, M. and Ghorbel, A. (2014) Management of Orbital and Endocranial Complications of Acute Bacterial Sinusitis. Journal Tunisien d ORL et de Chirurgie Cervico-faciale, 31, 1-6. 